\title{
Analisis CBR Tanah Clayshale Akibat Distabilisasi Semen
}

\author{
Edi Hartono ${ }^{\mathrm{a} *}$, Gilang Permana Santoso ${ }^{\mathrm{b}}$ \\ ${ }^{a}$ Program Studi Teknik Sipil, Fakultas Teknik, Universitas Muhammadiyah Yogyakarta \\ ${ }^{b}$ Program Magister, Universitas Muercu Buana
}

Riwayat Artikel
Diserahkan
27 Juni 2021
Direvisi
23 Agutus 2021
Diterima
20 Agustus 2021
*Penulis korespondensi
edi.hartono@umy.ac.id

\begin{abstract}
Abstrak
Clay shale merupakan batuan lunak yang memiliki potensi masalah pada kekuatan dan durabilitas bila tersingkap. Perbaikan tanah diperlukan bila digunakan sebagai lapis dasar jalan. Salah satu metodenya adalah stabilisasi menggunakan semen. Penelitian ini bertujuan untuk mengetahui perbandingan nilai CBR dan pengembangan clay shale sebelum dan sesudah penambahan semen. Semen yang ditambahkan sebesar $10 \%$ dari berat total tanah kering. Semen dicampur dengan metode dry mix dan spray mix. Pengujian CBR menggunakan 3 variasi pemadatan yaitu 10, 25, 56 kali pukulan. Hasil penelitian menujukkan bahwa penambahan semen $10 \%$ pada 56 pukulan akan meningkatkan nilai CBR 38,40\% dan menurunkan pengembangan 0,60\%. Nilai CBR dengan metode dry mix lebih tinggi dibandingkan dengan metode spray mix Kata-kata kunci: CBR, clayshale, stabilisasi semen, dry mix, dan spray mix
\end{abstract}

Kata kunci: CBR, clay shale, stabilisasi semen, dry mix, dan spray mix

\begin{abstract}
Clay shale is a soft rock that has potential problems in strength and durability when exposed. Soil Improvement Required when used as the subgrade. One of the repair methods is stabilization using cement. This study aims to determine the value of CBR and clay shale swelling after the addition of cement. Cement added by $10 \%$ of dry soil weight. The cement is mixed by dry mix and spray mix methods. CBR testing uses three variations of compaction 10,25, 56 blows. The results showed that adding 10\% cement and 56 blows increased the CBR value by $38.40 \%$ and decreased the swelling by $0.60 \%$. The CBR value with the dry mix method is higher than the spray mix method.

Keywords: CBR, clayshale, cement stabilization, dry mix, and spray mix

\section{PENDAHULUAN}

Dalam dunia konstruksi salah satu faktor yang Salah satu masalah pada pekerjaan konstruksi jalan adalah masalah tanah sebagai dasar konstruksi tersebut, khususnya padatanah-tanah lunak (Alhadar dkk., 2014). Indonesia merupakan salah satu negara dengan gunung api terbanyak akibatnya terbentuklah berbagai jenis tanah dari proses pengendapan dan pelapukan. Salah satu dari jenis yang ada adalah clay shale. Clay shale merupakan batuan sedimen berbutir halus yang terbentuk dari kelompok lempung akibat adanya tekanan. Agung dkk. (2015) juga menyebutkan bahwa clay shale sangat keras namun apabila sudah terbuka (exposed) terkena matahari, air, dan udara dalam jangka waktu yang tidak lama perilaku shale akan berubah menjadi soft clay $(\mathrm{mud})$. Proses ini otomatis mengakibatkan turunnya kuat geser tanah. Metode perbaikan dengan stabilisasi umumnya digunakan untuk meningkatkan kuat dukung tanah. Proses stabilisasi dilakukan agar tanah dasar masih dapat digunakan sehingga tidak diperlukan penggantian tanah.

Metode stabilisasi yang umum digunakan adalah metode pencampuran kering ( $d r y$ mix). Namun metode ini mempunyai kelemahan karena menimbulkan polusi saat pelaksanaan. Pakbaz dan Farzi (2014) mengkaji kuat tekan bebas tanah yang distabilisasi dengan metode pencampuran basah (slurry) dan pencampuran kering. Hasilnya menunjukkan kuat tekan bebas pencampuran basah lebih tinggi. Beberapa penelitian lain menunjukkan hasil yang sebaliknya, sehingga masih perlu dikaji pengaruh dari metode pencampuran ini. Penelitian ini membandingkan nilai CBR dan pengembangan clay shale tanpa penambahan semen dan dengan penambahan semen $10 \%$ dengan 2 metode pencampuran yaitu campuran kering (dry mix) dan campuran basah (spray mix). Pengujian CBR menggunakan 3 variasi energi pemadatan yaitu 10, 25, dan 56 kali tumbukan.

\section{METODE PENELITIAN}

\subsection{Tanah}

Penelitian ini menggunakan bahan utama berupa tanah berjenis clay shale. Tanah tersebutdiambil dari lokasi longsoran yang terletak di ruas jalan tol Semarang - Solo kurang lebih pada Seksi 2 (Ungaran - Bawen) km pada KM. $441+800$, Kabupaten Semarang, Provinsi Jawa 


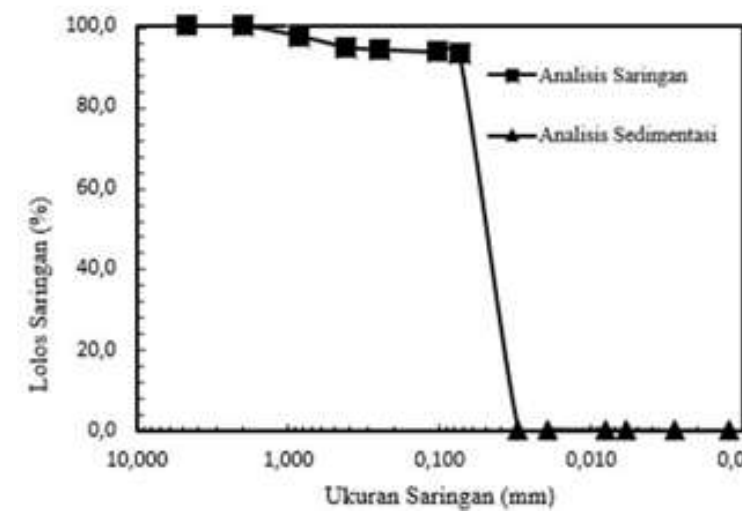

Gambar 1 Distribusi ukuran butir tanah clayshale.

Tengah. Sifat-sifatindeks tanah clay shale disajikan pada Tabel 1, sedangkan distribusi ukuran butiran tanah disajikan pada Gambar 1. Pengujian batas-batas konsistensi tanah umumnya menggunakan metode Casagrade (Muntohar, 2014a).

Tabel 1 Hasil pengujian sifat indeks tanah clayshale

\begin{tabular}{ll}
\hline Variabel Penelitian & Hasil Penelitian \\
\hline Berat Jenis (Gs) & 2,65 \\
Atterberg Limit & \\
Batas Cair (LL) & $57,87 \%$ \\
Batas Plastis (PL) & $28,40 \%$ \\
Batas Susut (SL) & $29,50 \%$ \\
Pemadatan Proctor & \\
Standard & \\
MDD & $16,33 \mathrm{kN} / \mathrm{m}^{3}$ \\
OMC & $19 \%$ \\
\hline
\end{tabular}

\subsection{Semen}

Penelitian ini menggunakan bahan tambah berupa semen Portland Composite Cement (PCC) merk Holcim yang telah sesuai dengan SNI 15-2049-2004. Menurut BSN (2004) dalam standar 15-2049 semen Portland adalah semen hidrolis yangdidapatkan melalui proses menggiling terak semen Portland yang terdiri atas kalsium silikat digiling bersama bahan tambahan berupasatu atau lebih kalsium sulfat dan bisa ditambahbahan lain. ASTM C12511 dalam Muntohar (2014b) menyebutkan semenPortland adalah suatu semen hidraulik dengan bahan penyusun utamanya adalah kalsium silikat hidrat (hydraulic calcium silicate).

\subsection{Pembuatan Benda Uji}

Penelitian ini menggunakan campuran semen 10\% dan variasi energi pemadatan 10 kali, 25 kali, 56 kali pukulan. Benda uji dibuat dari clay shale yang dihancurkan dan lolos saringan No. 4 dalam kondisi kering oven. Benda uji tanpa penambahan semen kemudian dicampurkan dengan air sebanyak 19\% dari berat total tanah kering secara merata menggunakan mixer. Tanah dan air yang telah tercampur dengan merata kemudian dipadatkan kedalam silinder CBR secara bertahap sebanyak 3 lapisan. Benda uji dengan penambahan semen $10 \%$ dibuat dengan 2 metode pencampuran yaitu kering (dry mix) dan basah (spray mix). Variasi pengujian dapat dilihat pada Tabel 2 .

Pada metode dry mix, tanah dan semen dicampur dalam kondisi kering kemudian ditambahkan air.

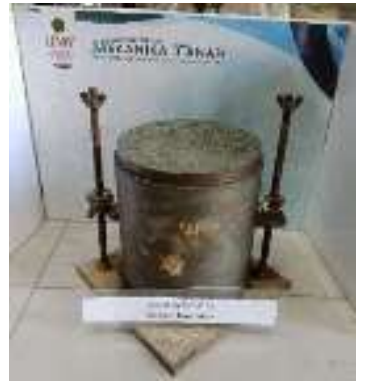

(a)

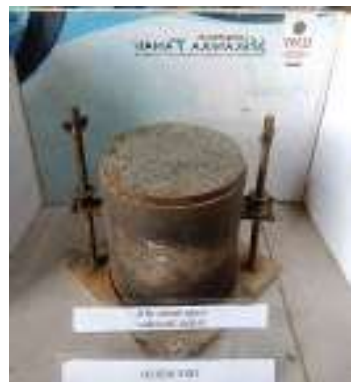

(b)

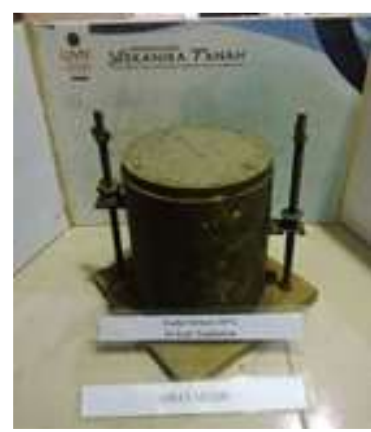

(c)

Gambar 2 Benda Uji yang telah dicetak (a) kadar semen 0\%, (b) kadar semen 10\% dry mix, (c) kadar semen 10\% spray mix

Sedangkan metode spray mix, tanah dicampur dengan sebagian air kemudian pasta semen (dengan FAS 0,7) disemprotkan kedalam adukan hingga merata. Semua benda uji, baik dengan atau tanpa semen, semua dicampur dengan jumlah air pada kondisi OMC. Benda uji yang telah tercetak kemudian diperam selama 7 hari dengan ditutup plastik. Benda uji 0\% dan 10\% dengan energi pemadatan 56 kali dapat dilihat pada Gambar 2.

Tabel 2. Variasi Pengujian

\begin{tabular}{lllllll}
\hline \multicolumn{4}{c}{ Dry Mix } & \multicolumn{4}{c}{ Spray Mix } \\
\hline & $10 \mathrm{x}$ & $25 \mathrm{x}$ & $56 \mathrm{x}$ & $10 \mathrm{x}$ & $25 \mathrm{x}$ & $56 \mathrm{x}$ \\
\hline $0 \%$ & $\bullet \bullet$ & $\bullet \bullet$ & $\bullet \bullet$ & $\bullet \bullet$ & $\bullet \bullet$ & $\bullet \bullet$ \\
\hline $10 \%$ & $\bullet \bullet$ & $\bullet \bullet$ & $\bullet \bullet$ & $\bullet \bullet$ & $\bullet \bullet$ & $\bullet \bullet$ \\
\hline
\end{tabular}

Keterangan : • jumlah specimen

\subsection{Pengujian CBR Laboratorium}

Menurut Andriyani dkk. (2012), definisi CBR (California Bearing Ratio) adalah suatu perbandingan antara beban percobaan (test load) dengan beban standar (standar load) dandinyatakan dalam persen. Penelitian ini mengunakan prosedur pengujian yang mengacu pada ASTM (1999) dalam standar D-1888 dalam kondisi rendaman. Benda uji yang telah diperam selama 7 hari kemudian direndam selama 4 hari guna mengukur pengembangan. Jafri dkk. (2014) menyebutkan bahwa hubungan antara potensi pengembangan (swelling) berbanding lurus dengan indeks plastisitas (PI), sehingga jika nilai indeks plastisitas (PI) tanah tinggi maka potensi pengembangan (swelling) tanah juga akan semakin tinggi pula begitu pun sebaliknya. Iqbal dkk. (2014) menerangkan bahwa CBR dengan rendaman (soaked) bertujuan untuk mendapatkan nilai CBR dalam keadaan jenuh air dan tanah mengalami pengembangan (swelling) 


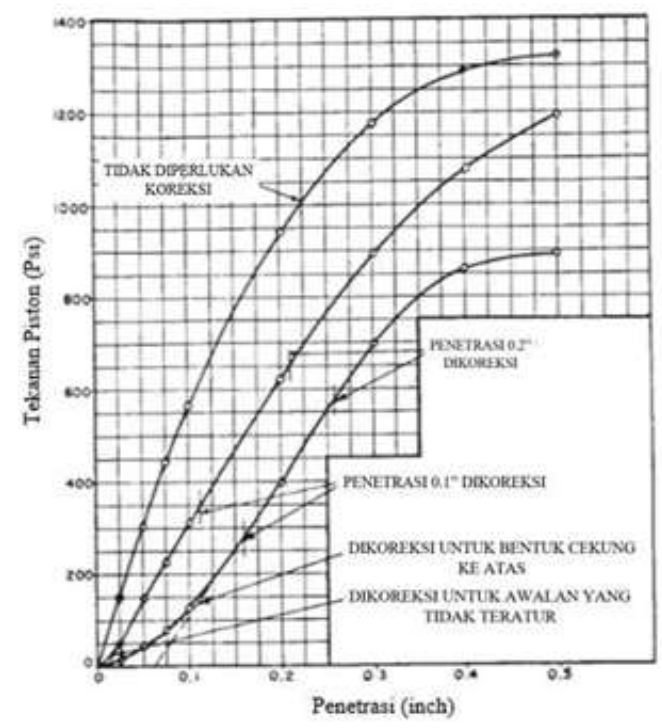

Gambar 3 Kurva dan koreksi CBR (ASTM,1999)

yang maksimum. Benda uji yang telah direndam kemudian dilakukan pengujian penetrasi CBR dan koreksi sesuai dengan Gambar 3. Nilai CBR didapatkan pada tekanan penetrasi 0,1 " dan 0,2 " terhadap tekanan penetrasi standar ditunjukkan pada Persamaan 1 dan Persamaan 2.

$$
\begin{aligned}
\mathrm{CBR}_{0,1 "} & =\left(\frac{P_{0,1^{\prime \prime}}}{1000}\right) \times 100 \\
\mathrm{CBR}_{0,2^{\prime \prime}} & =\left(\frac{P_{0,2^{\prime \prime}}}{1000}\right) \times 100
\end{aligned}
$$

dengan $\mathrm{CBR}_{0,1}$ " adalah nilai $\mathrm{CBR}$ pada penetrasi $0,1 \mathrm{inch}$,

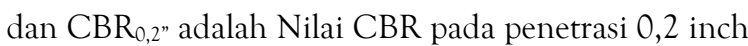

Kurva CBR yang dikoreksi apabila kurva berbentuk cekung keatas dan memiliki awalan tidak teratur. Nilai CBR yang digunakan adalah nilai CBR yang telah dikoreksi.

Nilai CBR yang umum digunakan adalah nilai $\mathrm{CBR}^{0,1}$. Nilai $\mathrm{CBR}^{0,2^{\prime \prime}}$ sering kali lebih besar dari nilai $\mathrm{CBR}^{0,1 "}$ maka pengujian perlu dilakukan ulang, namun apabila nilai $\mathrm{CBR}^{0,2^{\prime \prime}}$ tetap lebih besar maka nilai $\mathrm{CBR}^{0,2^{\prime \prime}}$ dapat dipergunakan sebagai nilai CBR tanah.

\section{HASIL PENELITIAN DAN PEMBAHASAN \\ 3.1 Pengembangan Tanah (Swelling)}

Pengujian pengembangan tanah dilakukan dalam durasi 96 jam dengan waktu pembacaan yang telah ditentukan. Kurva pengembangan tanah ditunjukkan oleh Gambar 4. Dari ketiga kurva pada Gambar 4 terlihat bahwa penambahan semen menurunkan pengembangan. Semakin besar energi pemadatan juga menurunkan pengembangan. Pada pukulan 56 kali (Gambar 4c), untuk kadar semen $0 \%$ didapat nilai swelling tertinggi sebesar 0,61\%, untuk kadar semen $10 \%$ dry mix didapatkan nilai swelling tertinggi sebesar 0,05\%, dan untuk kadar semen $10 \%$ spray mix didapatkan nilai swelling tertinggi sebesar 0,06\%. Menurut Widianti (2009) reaksi pozzolanik antara tanah dengan bahan tambah yang mengandung bahan pozzolan dapat menurunkan potensi pengembangan (swelling) tanah.
Hasil pengujian pengembangan tanah sangat dipengaruhi banyak faktor misal jenis tanah, metode pemadatan, metode pemcampuran, energi pemadatan, danlain sebagainya. Pengujian pengembangan tanah ini memiliki kecenderungan semakin banyak energi pemadatan dan penambahan semen maka nilai swelling tanah akan berkurang. Hal tersebut disebabkan karena rongga tanah akan memampat seiring dengan jumlah pukulan yang diberikan, sehingga tidak ada lagi pori-pori udara dan air yang menyelimuti tanah. Penambahan kadar semen dalam campuran tanah juga sangatmempengaruhi nilai pengembangan tanah. Hal itu disebabkan karena semen merupakan bahan pozzolan yang memiliki sifat mengeras biladiberi air (hidrasi) dan terjadi pertukaran ion- ion antara tanah dengan semen (aglomerasi) sehingga saat pencampuran dengan tanah, tanah ikut mengeras bersama dengan semen. Reaksi tersebut dinamakan reaksi pozzolanik.

\subsection{CBR (California Bearing Ratio)}

Pengujian CBR dilakukan dalam keadaan terendam (soaked), sebelumnya benda uji diperam selama 7 hari dan kemudian direndam selama 4 hari. Benda uji dibuat 3 buah benda uji setiap variasi. Gambar 5 menunjukkan kurva CBR semakin meningkat seiring dengan penambahan jumlah semen dan energi pemadatannya. Nilai CBR kadar semen 0\% lebih rendah dari pada kadar semen 10\%. Hal tersebut dipengaruhi oleh reaksi pozzolanik pada tanah dikarenakan penambahan semen. Penambahan semen pada tanah akan memperkuat daya rekat antar partikel tanah sehingga air tidak mudah untuk masuk kedalam tanah. Pandiangan dkk. (2016) menyebutkan peningkatan nilai CBR dikarenakan terjadi absorsi air dan pertukaran ion oleh semen menjadi lebih efektif dan cepat sehingga meningkatkan kohesi antar butiran tanah.

Tabel 3 Nilai CBR kadar semen 0\% dan 10\%

\begin{tabular}{cccc}
\hline \multirow{2}{*}{ Kadar Semen } & Pukulan & $\begin{array}{c}\text { CBR Rata } \\
\text { - Rata (\%) }\end{array}$ & \% Peningkatan \\
\hline \multirow{2}{*}{$0 \%$} & 10 & 2,84 & - \\
& 25 & 3,15 & - \\
\hline \multirow{2}{*}{ 10\% Dry Mix } & 56 & 5,67 & - \\
& 10 & 24,18 & 21,34 \\
& 25 & 26,25 & 23,10 \\
10\% Spray & 56 & 44,07 & 38,40 \\
Mix & 10 & 11,86 & 9,04 \\
& 25 & 25,43 & 22,28 \\
\hline
\end{tabular}

Tabel 3 dan Gambar 6 menunjukkan bahwa nilai CBR dengan menggunakan metode dry mix lebih tinggi dibandingkan dengan menggunakan metode spray mix. Hal ini dikarenakan tanah dan semen tercampur secara merata terlebih dahulu sebelum diberi air sehingga begitu terkena air, campuran tanah dan semen langsung bereaksi. Hasil ini sejalan dengan penelitian Dixon dkk. (2013) yang menyatakan bahwa stabilisasi semen dengan metode slurry mix menghasilkan nilai kuat tekan yang lebih rendah dibandingkan dengan metode dry mix. Pakbaz dan Farzi (2014) juga mengkaji metode pencampuran basah (slurry) dan pencampuran kering pada tinjauan kuat tekan bebas tanah yang distabilisasi. Namun hasilnya menunjukkan kuat tekan bebas pencampuran basah lebih tinggi. 


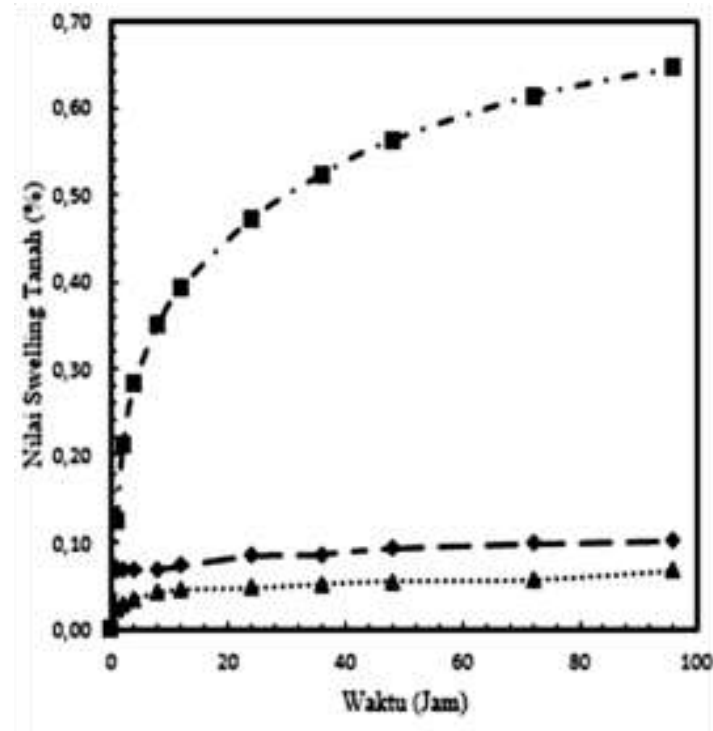

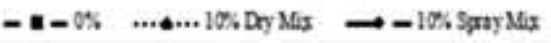

(a)

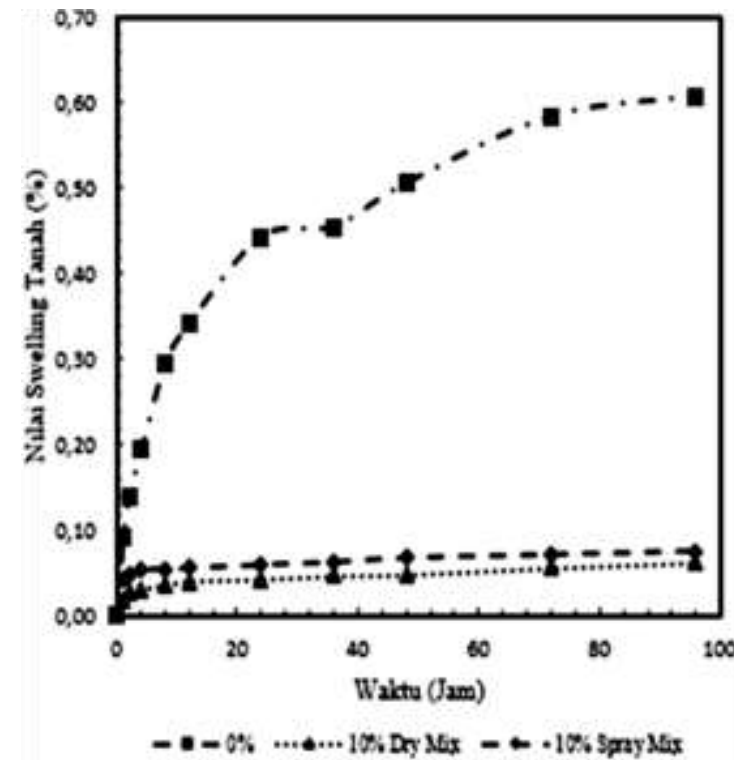

(b)

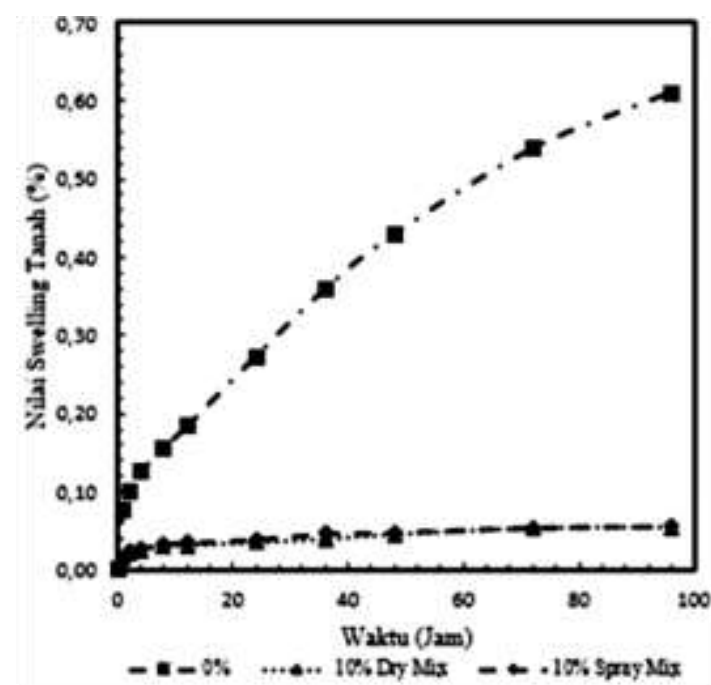

(c)

Gambar 4 Kurva hubungan nilai pengembangan tanah, (a) $10 \mathrm{x}$ pukulan, (b) $25 \mathrm{x}$ pukulan, (c) $56 \mathrm{x}$ pukulan

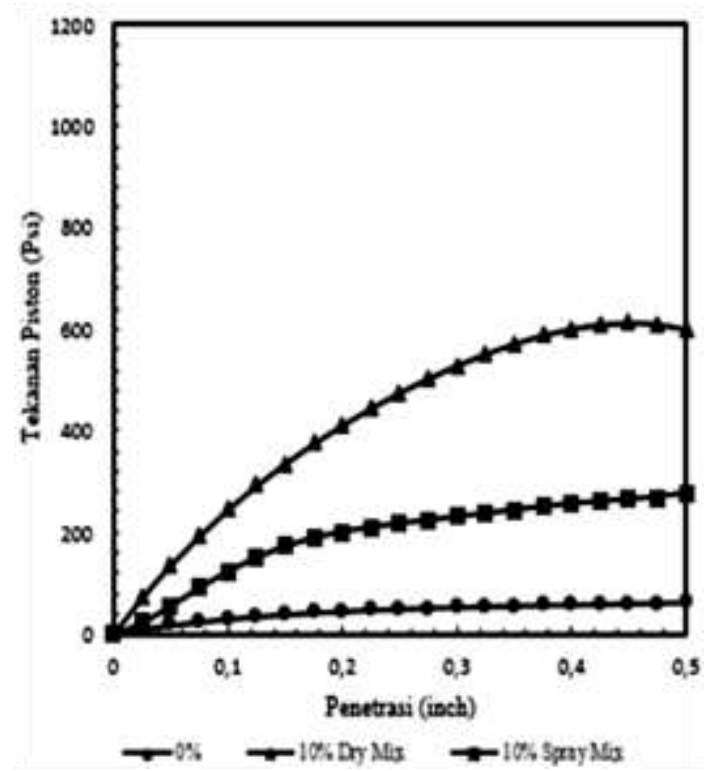

(a)
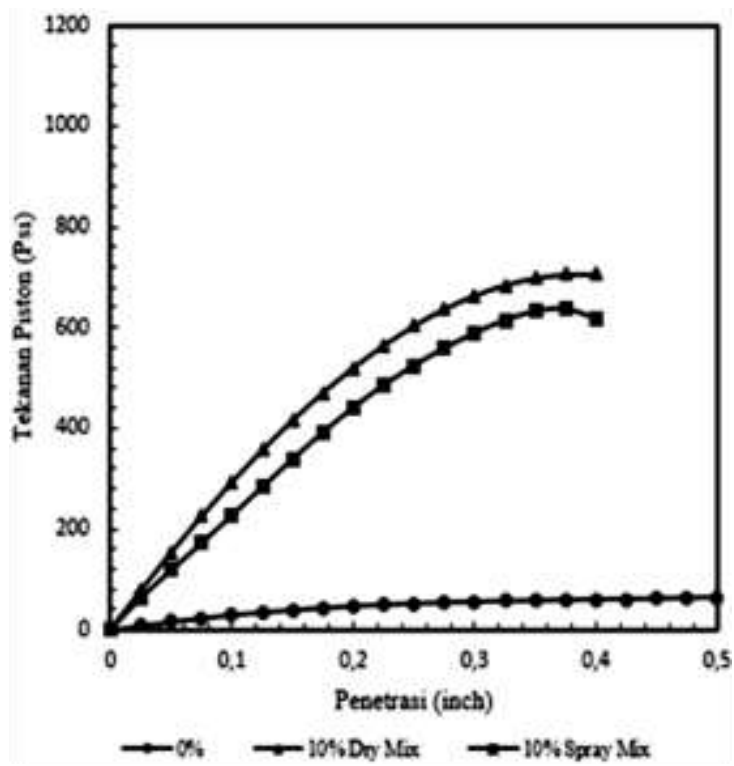

(b)

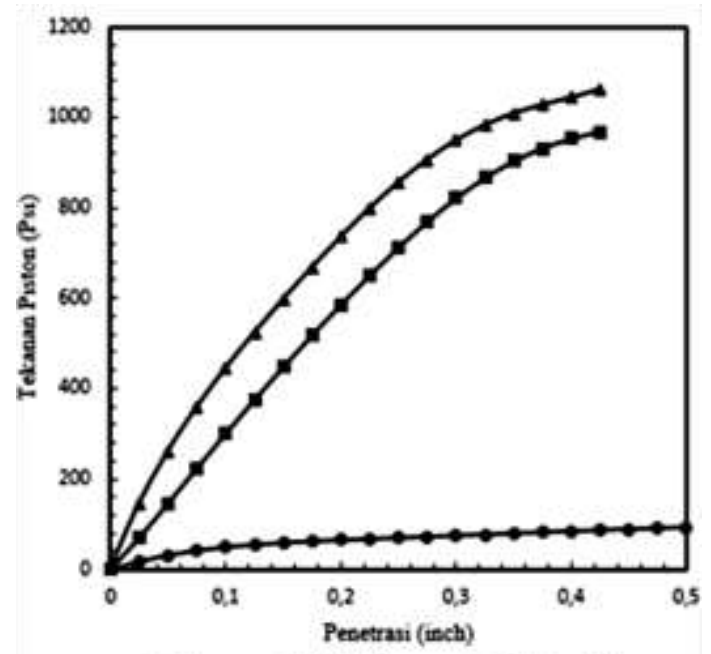

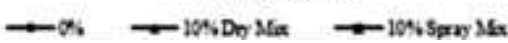

(c)

Gambar 5 Kurva hubungan tekanan piston dan penetrasi (a) jumlah pukulan 10x (b) jumlah pukulan 25x, (c) jumlah pukulan $56 \mathrm{x}$ 


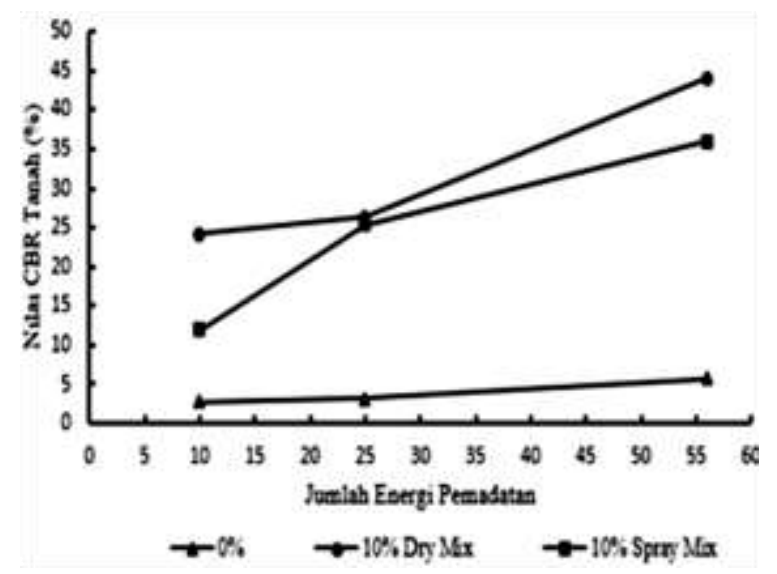

Gambar 6 Grafik hubungan nilai CBR tanah dengan jumlah energi pemadatan

Penambahan semen, baik dengan metode dry mix maupun spray mix meningkatkan nilai CBR sangat signifikan dan menurunkan pengembangan. Bila dipakai sebagai subgrade yang mempunyai syarat minimal CBR 6\% menurut SNI, maka clay shale yang distabilisasi memenuhi syarat sebagai subgrade.

\section{KESIMPULAN}

Berdasarkan hasil penelitian dan analisis yang telah dilakukan dapat ditarik kesimpulan bahwa penambahan semen pada campuran tanah akan meningkatkan nilai CBR (California Bearing Ratio) tanah. Nilai CBR mengalami peningkatan rata-rata 27,60\% dibandingkan dengan nilai CBR dengan kadar semen $0 \%$. Perbedaan metode pencampuran tanah dengan semen dapat mempengaruhi hasil pengujian CBR (California Bearing Ratio). Hasil penelitian menujukkan bahwa penambahan semen $10 \%$ pada 56 pukulan akan meningkatkan nilai CBR 38,40\% dan menurunkan pengembangan 0,60\%. Hasil pengujian CBR dengan menggunakan metode $d r y$ mix menghasilkan nilai CBR lebih tinggi dibandingkan menggunakan metode spray mix dengan ata-rata peningkatan 5,5\%.

\section{Daftar Pustaka}

Agung, P. M.A., Darmianto, B., Yuwono., dan Istiatun. 2015. A Critical State Approach To Stability Of Clay Shale For
Design Structures Of The Sentul Hill , West Java, Indonesia. The International 4th Conference of EACEF (European Asian Civil Engineering Forum) National University of Singapore, Singapore, 26-28 Juni 2013, 0-7.

Alhadar, S., Asrida, L., Prabandiyani, S., dan Hardiyati, S. 2014. Analisis Stabilitas Lereng Pada Tanah Clay Shale Proyek Jalan Tol Semarang-Solo Paket VI STA 22+700 Sampai STA 22+775. Jurnal Karya Teknik Sipil, 3(2), 336-344.

Andriyani, Yuliet, R., dan Fernandez, F. L. 2012. Pengaruh Penggunaan Semen sebagai Bahan Stabilisasi pada Tanah Lempung Daerah Lambung Bukit terhadap Nilai CBR Tanah. Jurnal Rekayasa Sipil, 8(1), 29-44.

ASTM, 1999, D1883-99: Standard Test Method for CBR (California Bearing Ratio) of Laboratory-Compacted Soils, ASTM International, West Conshohocken.

BSN, 2004, SNI-15-2049-2004: Semen Portland, Badan Standarisasi Nasional, Jakarta.

Dixon, P. A., Gutrhrie, W. S., dan Eggett, D. L. 2013. Factors Affecting Strength of Road Base Stabilized with Cement Slurry or Dry Cement in Conjunction with Full-Depth Reclamation. Transportation Research Record: Journal of the Transportation Research Board, 2310(1), 113-120.

Iqbal, M., Nugroho, S. A., dan Fatnanta, F. 2014. Pengaruh Kadar Lempung dan Kadar Air Pada Sisi Basah Terhadap Nilai CBR Pada Tanah Lempung Kepasiran (Sandy Clay). Jurnal Online Mahasiswa, 1(2), 1-12. Jafri, M., Setyanto., dan Aprinal, A. Ricky. 2014. Pengaruh Waktu Pemeraman terhadap Daya Dukung Stabilisasi Tanah Lempung Lunakmenggunakan TX-300. JurnalRekayasa, 18(3), 177 188 .

Muntohar, A. S., 2014a. Mekanika Tanah. Edisi ke-3. Yogyakarta : LP3M UMY.

Muntohar, A. S., 2014b. Prinsip-Prinsip Perbaikan Tanah. Yogyakarta : LP3M UMY.

Pakbaz, M. S., dan Farzi, M. 2014. Comparison of The Effect of Mixing Methods ( Dry Vs Wet) On Mechanical And Hydraulic Properties Of Treated Soil With Cement or Lime. Applied Clay Science, 105-106, 1-14.

Pandiangan, B., Iswan., dan Jafri, M. 2016. PengaruhVariasi Waktu Pemeraman Terhadap Daya Dukung Tanah Lempung dan Lanau yang Distabilisasi Menggunakan Semen pada Kondisi Tanpa Rendaman (Unsoaked ). JRSDD, 4(2), 256-275.

Widianti, A. 2009. Peningkatan Nilai CBR Laboratorium Rendaman Tanah dengan Campuran Kapur, Abu Sekam Padi dan Serat Karung Plastik, Jurnal Ilmiah Semesta Teknika, 12(1), 21-27. 
